\title{
Cistos Embrionários da Face
}

\author{
João Jorge D. Barbachan* \\ Manoel Sant'Ana Filho* \\ Pantelis Varvaki Rados* \\ Onofre Francisco de Quadros**
}

\section{INTRODUÇÃO}

As recentes modificações dos conceitos embriológicos, com respeito ao desenvolvimento dos processos maxilares, levou-nos a revisar este conteúdo exemplificando cada caso com material da Disciplina de Patologia da FO/UFRGS, enfatizando o diagnóstico correto como fase inicial e fundamental, para o tratamento.

Excluindo os cistos de origem odontoyênica devido a sua natureza diversa, A raújo (1) opta pela apresentação em relação a localização, uma vez que estas lesões variam de diaynóstico em função disto, mostrando vários outros aspectos em comum. Assim teremos:

Cisto da Maxila: Cisto do Canal Incisivo (da papila palatina), Palatino Mediano, Glóbulo-Maxilar e NasoLabial (Naso-alveolar).

Cisto da Mandíbula: e anexos, Cisto Mandibular Mediano, Linfoepitelial benigno, Dermóide e Epidermóide.

Cisto do Canal Incisivo (Naso-palatino e da Papila Palatina)

Lesão que se origina da inclusão de restos epiteliais no ducto de mesmo nome $(1,4,5,6,7,8,9)$, se localizando dentro do canal, quando é chamado de naso-palatino, ou na sua porção mais externa, chamado, Cisto Papila Palatina. Do ponto de vista clínico em geral é assintomático, salvo se infectado secundariamente, quando apresenta drenagem de pus, dor e aurnento de volume (Fig. 1). O exame radiográfico mostra imagem radiolúcida arredondada, na região anterior da maxila, entre os incisivos centrais, cujo aspecto mais característico é em forma de coração, determinado pela projeção da espinha nasal anterior (11). (Fig. 2).

\section{Cisto Naso-Alveolar (Naso-Labial)}

Origina-se na junção dos processos globular, nasal lateral e maxilar, pela proliferação de restos epiteliais af aprisionados $(1,4,5,7,8)$. Para Lucas (6) entretanto, esta explica- ção está sendo descartada e tem sido sugerida a origem a partir da porção mais inferior do ducto nasolacrimal. Do ponto de vista clínico se apresenta como aumento de volume localizado próximo da inserção da asa do nariz sobre a maxila, elevando-a e algumas vezes distendendo o sulco naso-labial (Fig. 3). O lábio superior também pode estar tumefacto em função da evolução da lesão (Fig. 4). Em se tratando de lesão de tecidos moles, na maioria das vezes não há alteração radiográfica, salvo se pelo seu desenvolvimento desencadear reabsorção na porção mais anterior da maxila ou pela utilização de contraste radiográfico (Fig. 5). Este procedimento visa o estabelecimento das relações entre a patologia e os tecidos adjacentes, principalmente no sentido ântero-posterior.

\section{Cisto Glóbulo-Maxilar}

Esta lesão tem sido descrita classicamente como de origem fissural $(1,4,5,7,8)$, desenvolvendo-se a partir de epitélio embrionário retido na junção dos processos globular (pré-maxila) e maxilar. A partir dos estudos embiológicos de Christ (2), se questiona a presença de restos epiteliais nesta fusão. A análise de casos feita por outros autores (apud Shear) baseados na revisão das ca- racterísticas clínicas, radiográficas e histopatológicas chega a dignósticos diversos ao de Glóbulo-Maxilar e sugerem que na realidade tratase de variadas lesões que podem se localizar nesta região, assumindo características particulares, que são, do ponto de vista clínico descobertas acidentalmente ou pelo aumento de volume provocado. Seu aspecto mais marcante é o radiográfico que, segundo Souza (11) mostra uma área radiolúcida, unilocular, localizada entre incisivo lateral e canino, mostrando uma marcada inclinação destes dentes com afastamento das raízes, aproximação das coroas (5), tomando a forma de pera invertida (8). (Fig. 6).

\section{Cisto Linfoepitelal Benigno (Branquial)}

Lesão de histogênese também discutida, se de restos epiteliais aprisionados em linfonodos cervicais, oriundos possivelmente de glândulas salivares, ou de remanescentes epiteliais de arcos branquiais $(1,4,8,9)$. Localiza-se mais freqüentemente na porção lateral do pescoço, superficial, próximo à borda anterior do músculo esternocleidomas-

\footnotetext{
*Prof. de Patologia da UFRGS e PUCRS

**Prof. de Patología e Estomatologia da UFRGS
} 


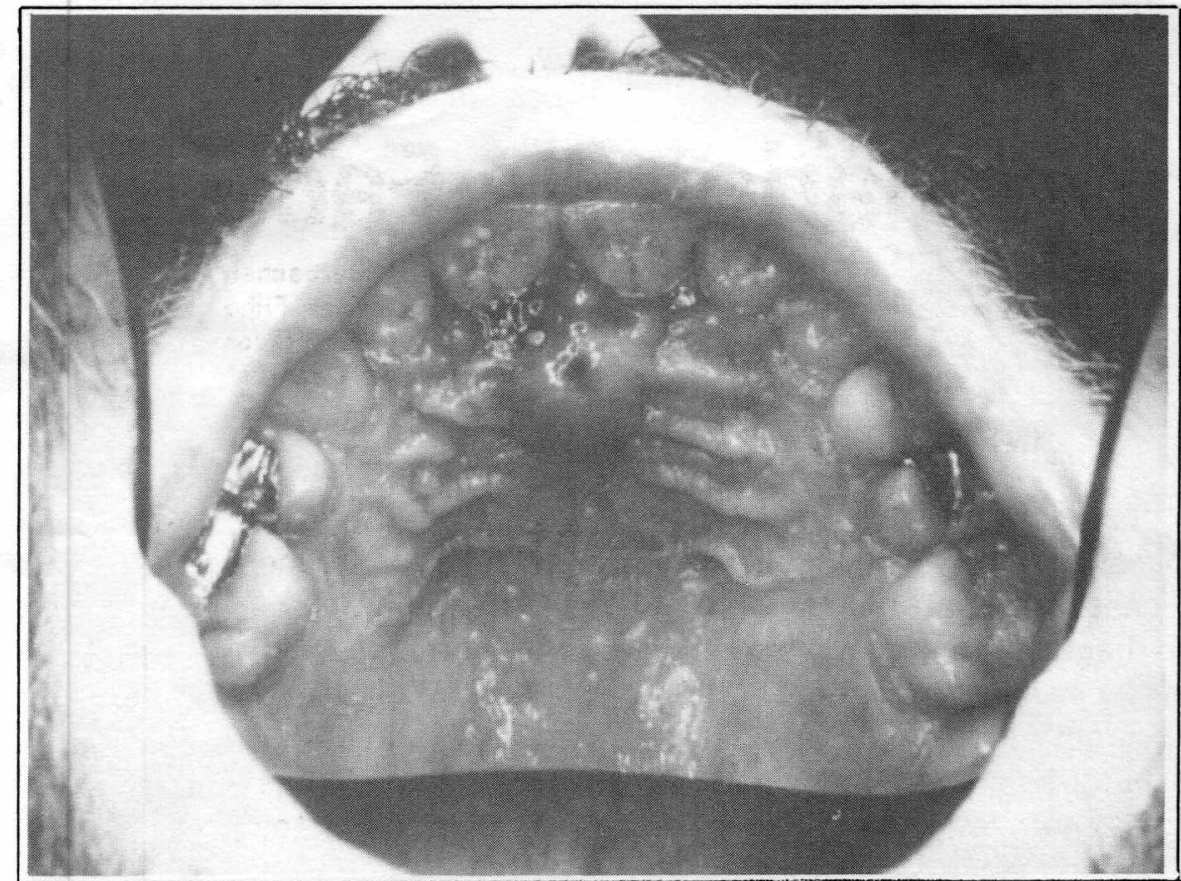

FIGURA 1 - Aspecto clínico de Cisto do Canal Incisivo.

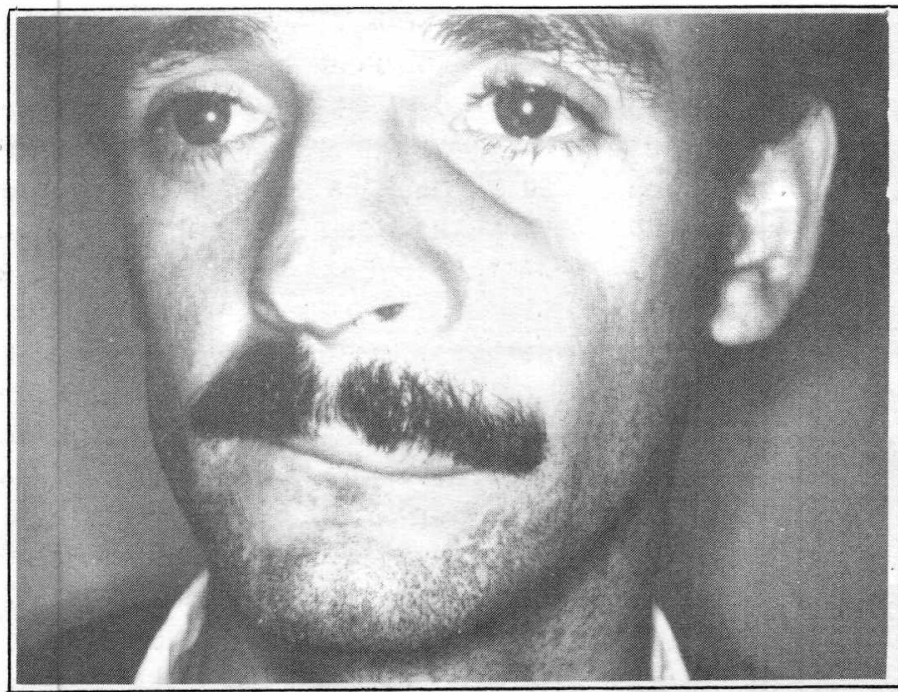

FIGURA 3 - Aspecto clíniøo extra bucal de Cisto Naso-Labial.

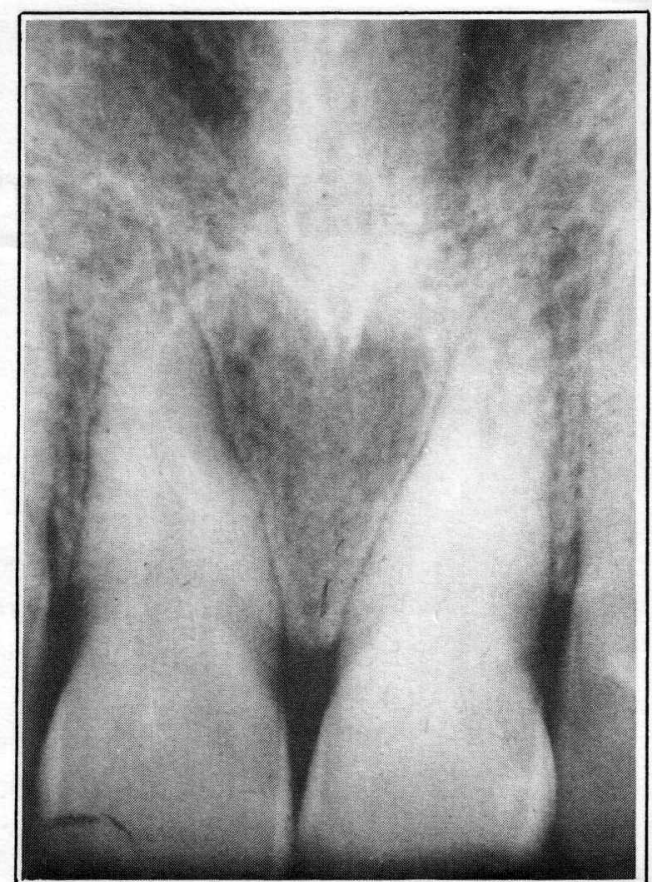

FIGURA 2 - Aspecto radiográfico da Fig. 1.

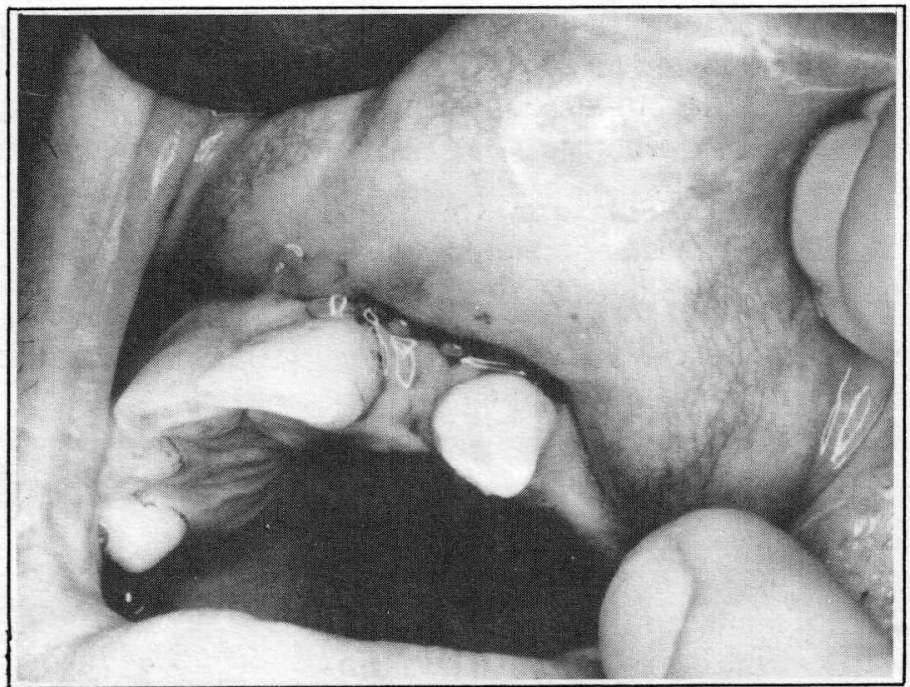

Figura 4 - Aspecto cilinico intra bucal de Cisto Naso-Labial.

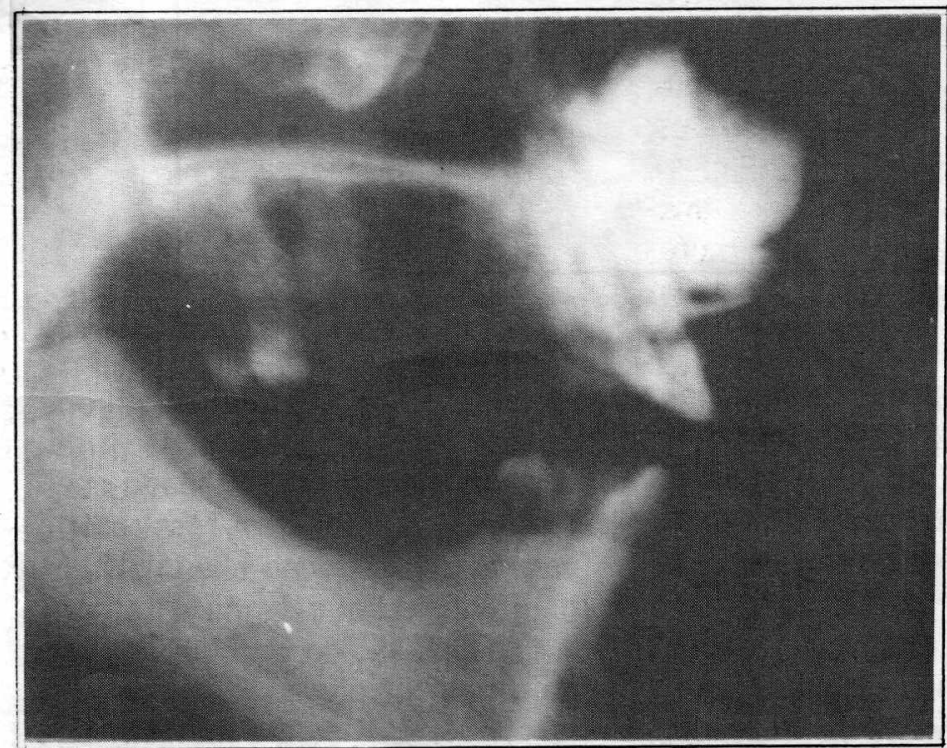

FIGURA 5 - ASpecto radiográfico de Cisto NasoLabial ap6s injeção de Contraste (Gentileza Prof. Icléo F. Souza). 


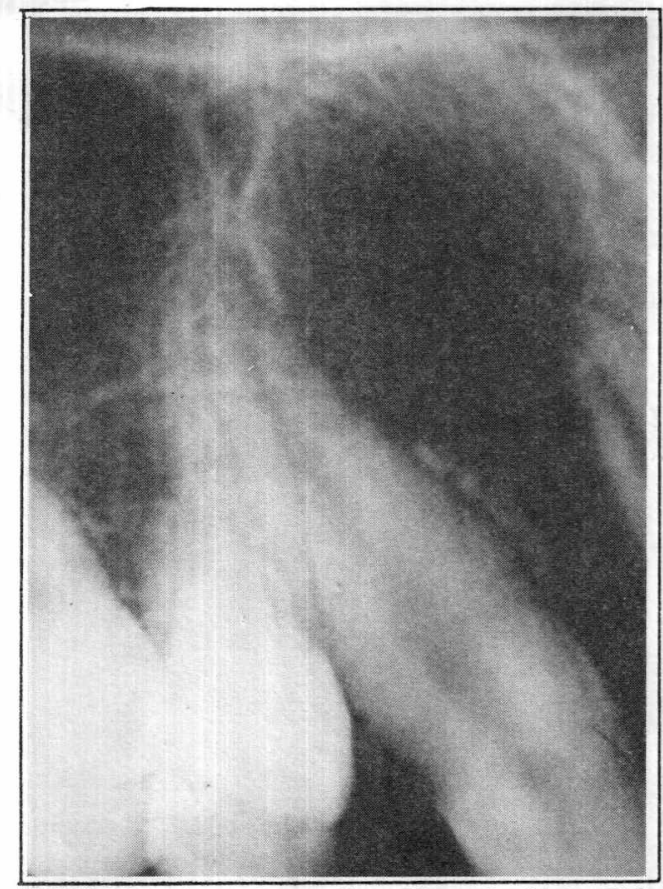

FIGURA 6 - Aspecto radiográfico de Cisto GIóbulo-Maxilar.

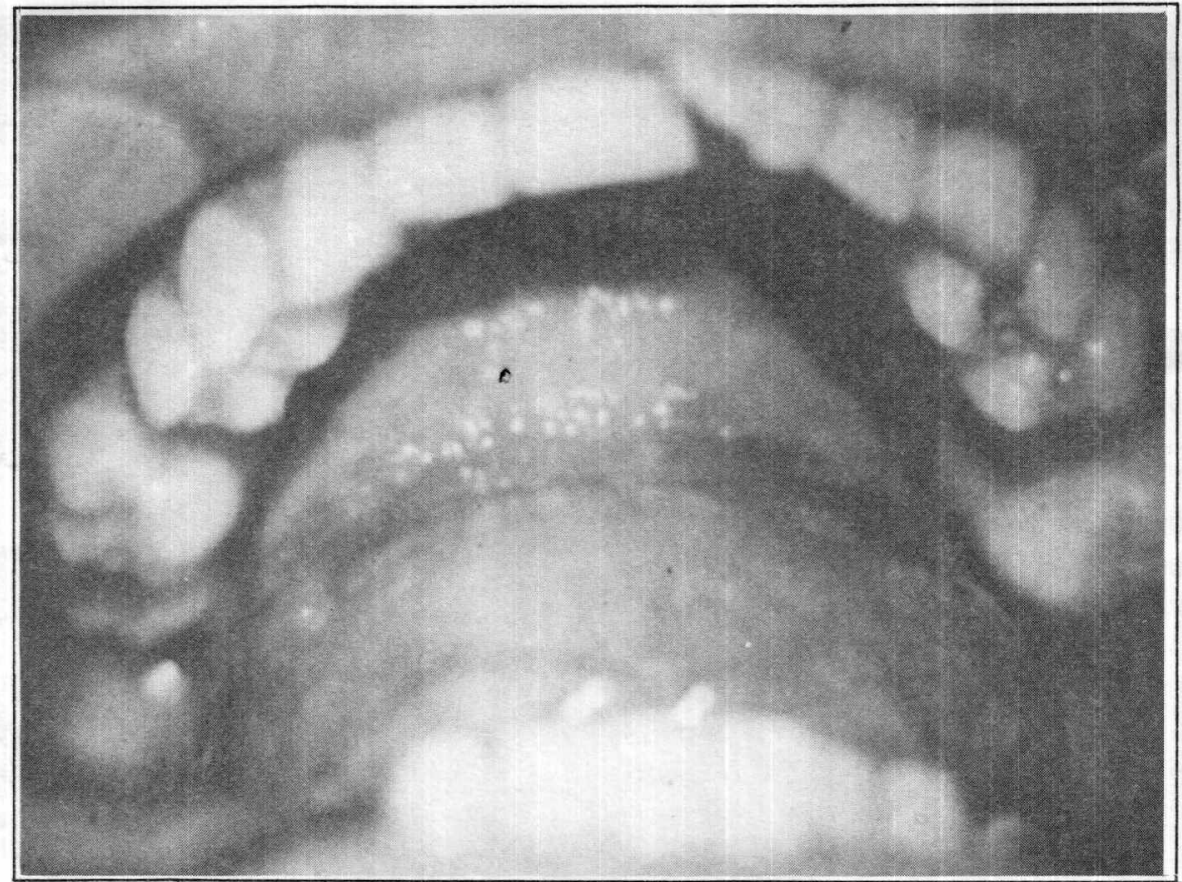

FIGURA 8 - Aspecto clínico intra bucal de Cisto Epidermóide (Gentileza do Dr. José Luiz Piazza).

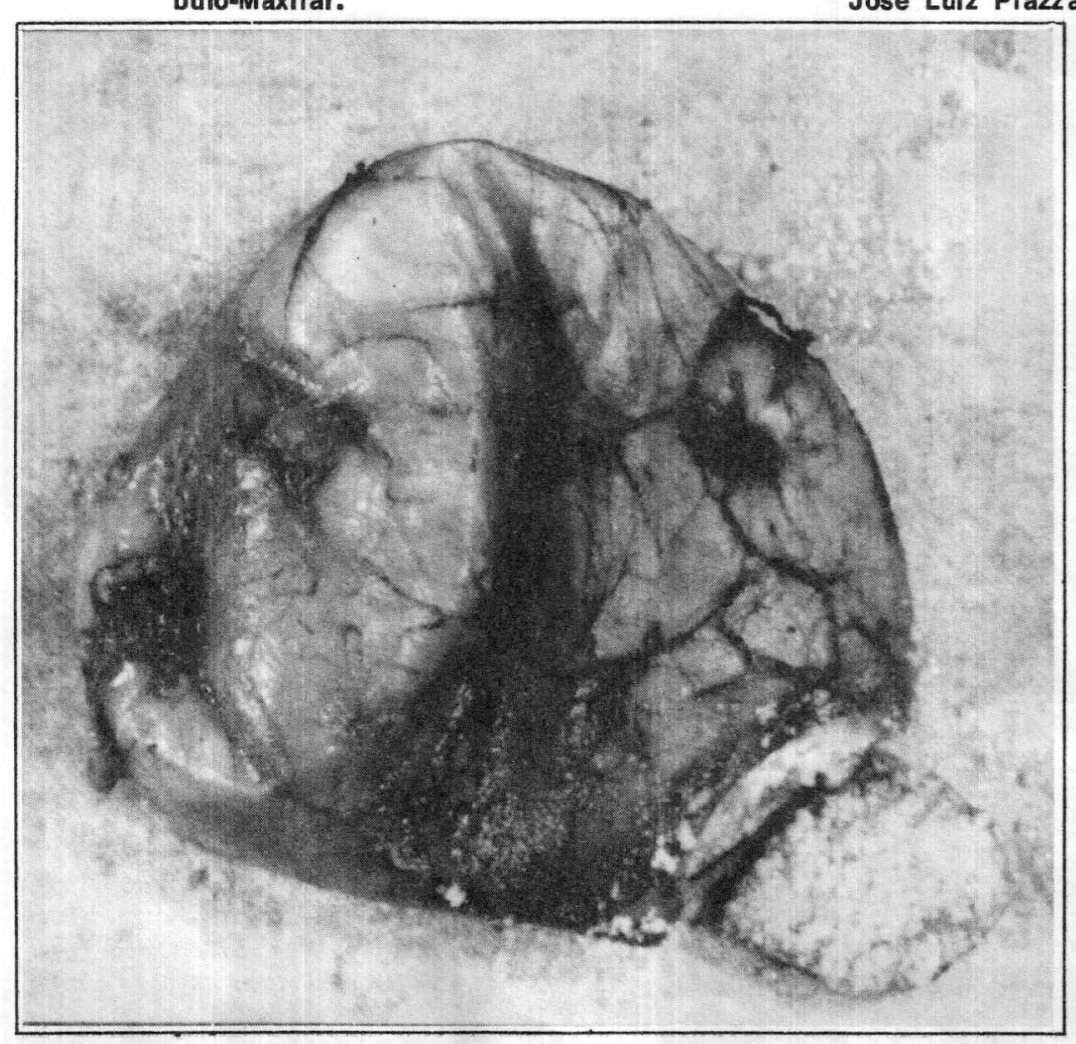

FIGURA 11 - Aspecto macroscópico, mostrando ceratina no interior da lesão.

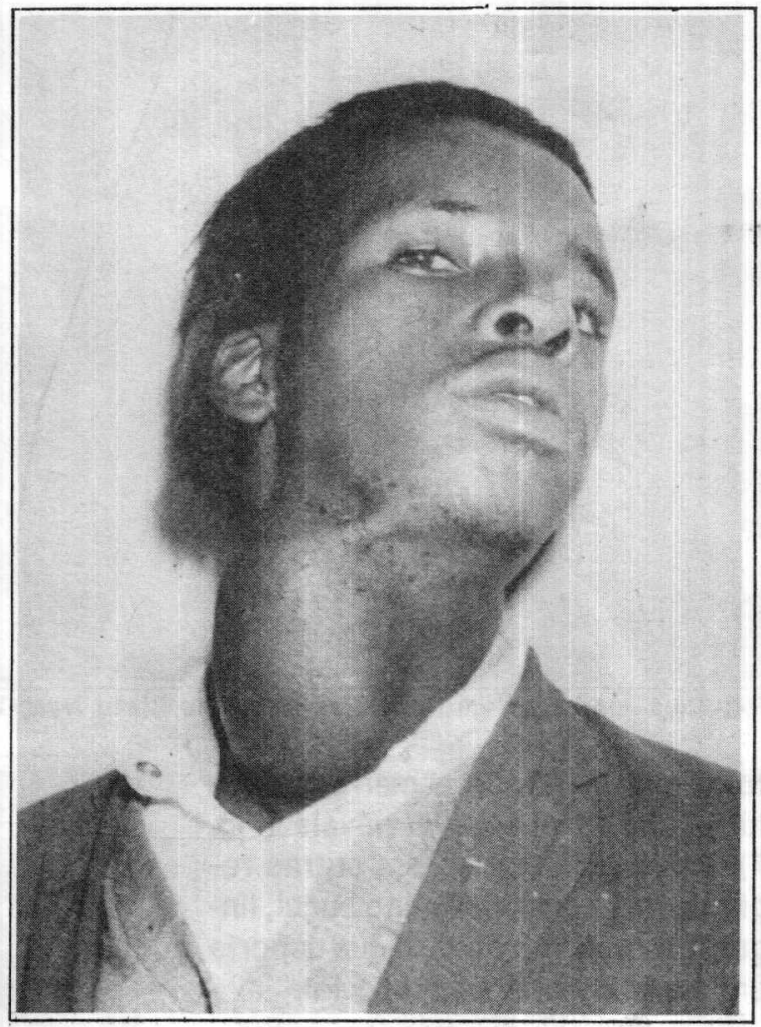

FIGURA 7 - Aspecto clínico de Cisto Linfoepitelial Benigno.

da região, pode provocar abaulamento submental (Fig. 9). Em geral é bem delimitado (Fig. 10) e uma característica importante é a presença de ceratina no seu interior, visível clinicamente (Fig. 11). Em se tratando de verdadeiros cistos, são lesões que apresentam microscopicamente tecido epitelial revestindo cavidade, circundado por tecido conjuntivo fibroso. O tipo de epitélio pode variar, de revestimento (estratificado pavimentoso) ou do tipo respiratório (pseudo estratíficado cilado). 0 cisto Linfoepitelial benigno apresenta, na cápsula, tecido linfóide com arranjo semelhante ao linfonodo (8). Os cistos Dermóide e Epidermóide apresentam ceratina no interior da cavidade e a distinção entre ambos é feita pela presença de anexos cutâneos (glândulas sebáceas, sudoríparas, folículos pilosos) no primeiro.

Quanto ao tratamento é cirúrgico com eliminação de toda lesão que em geral é circunscrita (Fig. 10) e o acesso preferencial é o intrabu- 
cal excessão feita ao dermóide e epidermóide e linfoepitelial benigno, quando localizados superficialmente na pele.

\section{DISCUSSÃO}

A dificuldade de diagnóstico destas Isões parece não existir, em função do conhecimento bem difundido das suas características. Porém é importante percebermos que este diagnóstico só fica facilitado devido ao somatório de todas as características e que a ausência de qualquer destes aspectos (clínico, radiográfico e histopatológico) quase impossibilita o diagnóstico; isto fica mais evidente quando tomamos o cisto glóbulo maxilar: a maioria dos casos com este diagnóstico quando revisados pelos autores (9), levando em conta todas as caracteristicas modificou o diagnóstico inicial e conseqüentemente sua patogenia. Como exemplo, a Fig. 6 mostra um típico cisto glóbulo maxilar, porém este caso foi acompanhado previamente e no primeiro momento (Fig. 12) 0 aspecto era de cisto dentígero, e que nos leva a concordar com os autores $(2,9)$ de que talvez lesões al localizadas tomam aspecto peculiar do ponto de vista radiográfico mas não necessariamente é uma lesão distinta.

\section{CONCLUSÃO}

Apesar de serem lesões de aparente simplicidade de diagnóstico, este só é viável mediante a associação de todas as suas características.

\section{RESUMO}

Os autores apresentam casos de Cistos não odontogênicos da boca e anexos abordando todas as suas caractetrísticas e enfatizando o somatório destas para o correto diagnóstico.

\section{SUMMARY}

Cases of non-odontogenic cysts of mouth are presented, enfazing the necessity of all their aspects to get the correct diagnosis.

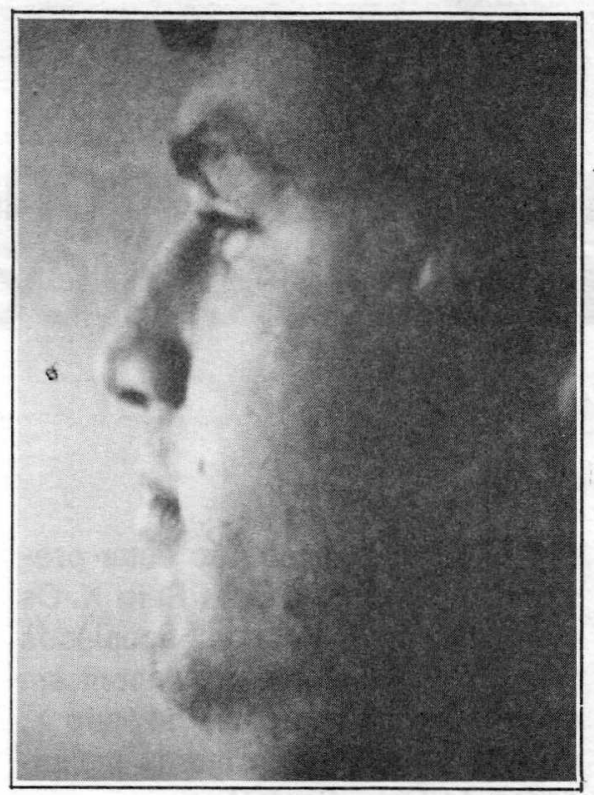

FIGURA 9 - Aspecto clinico extra bucal de Cisto Epidermóide (Gentileza do Dr. José Luiz Plazza).

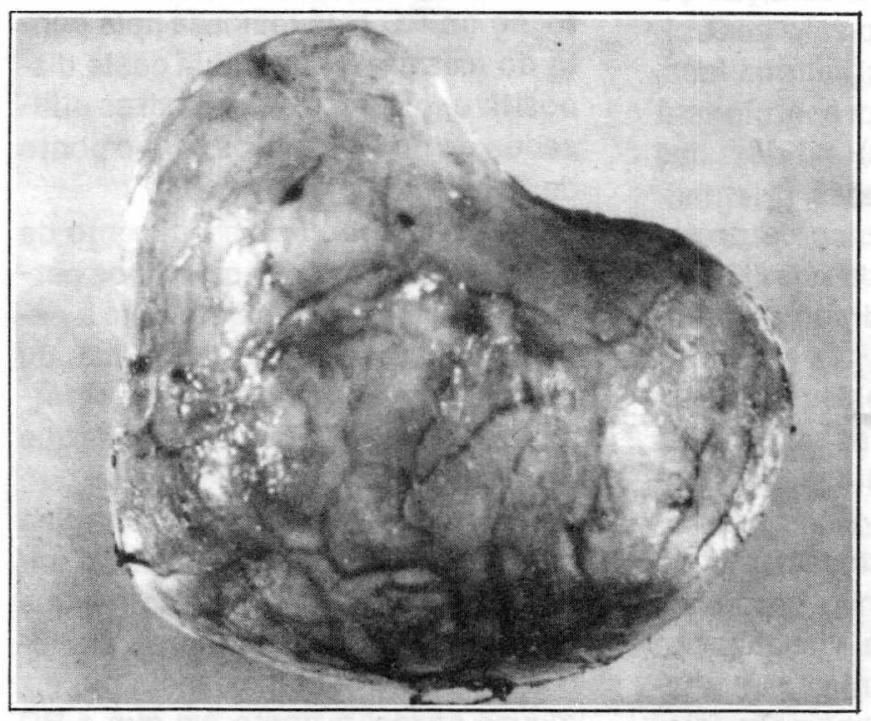

FIGURA 10 - Aspecto macroscópico das Figs. 8 e 9.

\section{REFERÊNCIAS BIBLIOGRÁFICAS}

1. ARAUJO, N. S. e ARAUJO, V.S. Patologia Bucal, Artes Médicas, 1984.

2. CHRIST, T.F. The Globulomaxillary cyst - An Embriologic Misconception. Oral Surg. 30, 515-526, 1970.

3. GLICKMAN, R. et alli. An Adenomatoid Odontogenic Tumour Simulating GlobuloMaxillary Cyst. J. Oral Med. 38:26-30, 1985.

4. GORLIN, RoJ. e GOLDMANN, M.M. Patologia Oral de Thoma. 6_ed., Barcelona, Salvat Editores, 1973.

5. KILLEY, H.C. e KAY, LoM. Benign Cystic Lesions of the Jaws. London, E. e S. Livingstone Ltd, 1966.

6. LUCAS, R.B. Pathology of Tumours of the Oral Tissues. 4.ed., London, Churchill Livingstone, 1984.
7. PINDBORG, J.J. e KRAMER, I.R.H. Histological Typing of Odontogenic Tumours, Jaw Cysts, and Allied Lesions. NHD, Geneva, 1971.

8. SHAFER, N.G., HINE, M.K. e LEVY, B.M. Tratado de Patologia Bucal. 4.ed., Rio de Janeiro, Interamericana, 1985.

9. SHEAR, M. Cysts of the Oral Regions. 2.ed., Bristol, Wright - PSG, 1983.

10. SMITH, R.A.; KATIBAH, RoN. e MERRELL, P. Nasolabial Cyst: Report of a case. J. Canad. Dent. Ass., 11:727-729, 1982.

11. SOUZA, I.F. Aspectos Radiográficos das Lesőes Ósseas Maxilo Mandibulares In FREITAS, A.; ROSA, J.E. e SOUZA, I.F. Radiologia Odontológica, Artes Médicas, 1984. 